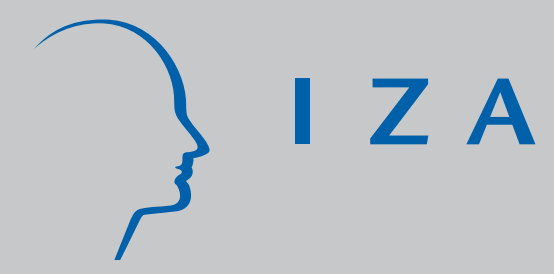

IZA DP No. 3546

Household Membership Decisions of Adult Children

Maria Concetta Chiuri

Daniela Del Boca

J une 2008 


\title{
Household Membership Decisions of Adult Children
}

\author{
Maria Concetta Chiuri \\ University of Bari, CSEF and CHILD \\ Daniela Del Boca \\ Collegio Carlo Alberto, CHILD, \\ University of Turin and IZA
}

\section{Discussion Paper No. 3546 \\ June 2008}

\author{
IZA \\ P.O. Box 7240 \\ 53072 Bonn \\ Germany \\ Phone: +49-228-3894-0 \\ Fax: +49-228-3894-180 \\ E-mail: iza@iza.org
}

\begin{abstract}
Any opinions expressed here are those of the author(s) and not those of IZA. Research published in this series may include views on policy, but the institute itself takes no institutional policy positions.

The Institute for the Study of Labor (IZA) in Bonn is a local and virtual international research center and a place of communication between science, politics and business. IZA is an independent nonprofit organization supported by Deutsche Post World Net. The center is associated with the University of Bonn and offers a stimulating research environment through its international network, workshops and conferences, data service, project support, research visits and doctoral program. IZA engages in (i) original and internationally competitive research in all fields of labor economics, (ii) development of policy concepts, and (iii) dissemination of research results and concepts to the interested public.
\end{abstract}

IZA Discussion Papers often represent preliminary work and are circulated to encourage discussion. Citation of such a paper should account for its provisional character. A revised version may be available directly from the author. 


\section{ABSTRACT \\ Household Membership Decisions of Adult Children ${ }^{*}$}

While several social, economic and financial indicators point to a growing convergence among European countries, striking differences still emerge in the timing of leaving home for adult children. In Southern countries (as Spain, Italy or Portugal) in 2001 more than 70 percent of young adults between 18 and 34 years of age live with their parents, whereas the corresponding number for Northern countries (like Denmark or the UK) is well below 40 percent. Existing literature highlights several factors explaining the different patterns in Europe: preferences and culture, labor market conditions, housing market as well as differences across the welfare states. In our work, we consider living arrangements of people 18-34 years old from 14 European countries (ECHP). We augment the informational content with indicators of labor, housing and marriage markets characteristics as well as proxy for the welfare states and culture. We investigate how they are intertwined with gender differences

JEL Classification: J13, C41, H53

Keywords: living arrangements, duration analysis, government expenditures

Corresponding author:

Daniela Del Boca

Department of Economics

University of Turin

Via Po 53

10124 Turin

Italy

E-mail: dani.delboca@unito.it

\footnotetext{
* This research has been partly supported by Italian Ministry of University and Research (MIUR, PRIN 2006). This research has been undertaken when Maria Concetta Chiuri was Visiting Fellow at the Collegio Carlo Alberto. We thank Collegio Carlo Alberto for hospitality and support and Salvatore Nunnari for excellent research assistance. Earlier versions of the paper have been presented at the Max Planck Institute in Rostock, the Conference on the Family in Florence and ESPE2008 Meeting in London. We are grateful to Christopher Flinn, Christine Hauser, and David Card for helpful discussions.
} 


\section{Introduction}

While several social, economic and financial indicators point to a growing convergence among European countries, striking differences still emerge in the timing of leaving home for adult children. As Figure 1 illustrates, in Southern countries, such as Spain, Italy and Greece, more than 70 percent of young adults between 18 and 34 years of age lived with their parents in 2001, whereas the corresponding number for Northern countries, like Denmark and Finland, was well below 40 percent.

There are several reasons for young adults to leave home and to settle in a new living arrangement. Some of them leave home to move in with a partner, others leave to pursue higher education, some settle in a different area due to their job, whereas others simply desire independence (either living alone or sharing a flat with other house-mates).

However, the existing differences across countries reflect the presence of cultural characteristics related to the strength of inter-generational ties as well as economic differences which constrain in various ways households' choices. For instance, in several countries young adults are more likely to attend higher education and encouraged to attend higher education at universities with on-campus accommodation, while in other countries local universities are widespread and their proximity provide strong incentives for young adults to co-reside with their parents for longer period of time. Similar considerations regard the different characteristics of the housing and mortgage markets. Different regulations across countries affect the development of mortgage markets, the availability of housing and the age at which young individuals buy their homes (see Chiuri and Jappelli, 2003). Needless to say that in some Southern European countries employment protection legislation systems favoring in job adult workers combined with a severe lack of social policies instruments might have induced younger workers to cohabit with their parents in order to enjoy intra-household income transfers and insure against unemployment risks.

While documenting the role of markets, public institutions and culture for each European country, we also explore how they interrelate with gender differences as we find a common international pattern: young women leave home earlier than men.

A further contribution of this paper is that we can study the determinants of youth living arrangements exploiting a large international dataset on households, complementing its informational content with indicators of local marriage markets and labor markets and controlling for other potential effects, such as country differences in financial markets imperfections, welfare state and social values.

Some might argue that cross-country differences depend in large part on the prevailing views of intergenerational relationships as well as, more in general, on 
cultural traits within each society. However, in this analysis, while we take into account the differences of institutional arrangements we consider them as exogenous in order to focus on the impact of personal, family, economic and labor market situation of young adults on the propensity to leave home.

In what follows, in Section 2 we review various reasons why the coresidence rates can vary across countries and above all we deal with some institutional features of marriage markets, labor and financial markets, welfare systems and culture. In Section 3 we present the microeconomic data set and the characteristics of the sample. The heart of the paper is in Sections 4 and 5, where we present our econometric strategy and discuss the empirical estimates. We find that personal and household characteristics as well as institutional settings remarkably determine the choice of coresidence patterns. Moreover, ceteris paribus, the size of their impact differ with gender. Understanding the reasons for the differences in coresidence patterns has important policy implications. Section 6 summarizes the evidence found and draws some policy conclusions.

\section{What determines different living arrangements?}

Existing theoretical models mainly view coresidence as the result of a non-cooperative game between parents and children. They usually assume that children value their independence and, everything else being equal, would live on their own. However, in case of coresidence parents and children share income, as well as housing and domestic goods. Thus their final optimal choice would also depend on respectively parents and children utility levels in the outside option, i.e. the case of separate living arrangements.

Previous theoretical and empirical research analyzed how poor institutional and markets characteristics might lower the utility from living alone, rendering more appealing the coresidence choice. In particular, in analyzing the living arrangements of young adults across European countries several approaches have been proposed.

A first line of research has focused on family income and labour market conditions. In particular, the youth labor market conditions are important determinants of young individuals living arrangements and various authors have emphasized the role of the family as an insurance mechanism against employment risk (see Card and Lemieux, 2000, Rosenzweig and Wolpin, 1993, Fogli, 1999 and Becker, Bentolila, Fernandes and Ichino 2005). Thus, youths would stay as a mean of obtaining the insurance that the market would not supply them.

Both studies of Card and Lemieux (2000) and Rosenzweig and Wolpin (1993) find that the probability of living with parents increases when negative income shocks 
occur, as it is higher among unemployed and low-income groups in Canada and the US. In particular, Card and Lemieux find that poor labor market conditions in Canada explain why the fraction of youth living with their parents has recently increased in Canada relative to the US.

Becker et al. (2005) test whether coresidence is associated with higher job insecurity. In other words, young adults when facing income risks are more likely to postpone irreversible choices, such as household formation. They use aggregate evidence for 13 European Union member countries on co-residence rates and perceived job insecurity and according to their estimates, for every 10 percentage-point rise in the percentage of youths feeling that their job is insecure, the co-residence rate increases by 1.5-1.7 percentage points. The underlining theoretical model can be found in Fogli (2004). She shows by means of an overlapping generations model that coresidence is the optimal solution when young adults are credit constrained and the legislation that protects the employment of mature workers is more strict. The results found in Becker et al. as well as in Card and Lemieux can be explained if parents are altruistic and share income risks with their children.

The working status of parents, especially the mother's one, appears to be another important factor. In McElroy (1985) theoretical model the reservation wage of young adults who live with their parents, and their utility as a member of their parents' household, decrease with their mother's wage. Therefore, as their mother's wage increases, their probability of moving out increases as well. Cantó-Sánchez and Mercader-Prats (1996) and Diaz and Guillo (2005) find that children living in households where both parents are working may experience low unemployment rates, whereas those living in households where the mother is not working, or she is just a discouraged seeker, will experience high unemployment rates.

In order to understand the determinants of youths' home leaving decision we need to take into account that their response to their mother's market activity differs greatly from their response to their father's. There might be several explanations supporting this view. On one hand a working mother reduces the amount of goods and services produced in the household, rendering less appealing living with parents; on the other, her status increases the household income, providing a better insurance to all members. Mother's working status can also be interpreted as a proxy for the family attitude towards women independence. A household that views women working in the labor market favorably may support children's early independence (Del Boca et al. 2000, Fernandez et al. 2005, Farrè and Vella, 2007). Finally, a working mother may serve as a role model for daughters' labor market behavior.

Another important factor affecting the cost of children leaving the parental home has to do with the housing market. Analyzing European data (the European Com- 
munity Household Panel), Martins and Villanueva (2006) test whether limited access to credit markets explains why young adults live with their parents. They show that differences in credit market imperfections within Europe can explain up to 20 percent of the cross- country variance of establishing a new household. In particular, they stress the importance of access to housing in order to leave the parental home. Similar results emerge in individual countries research. Ermisch (1999) for the UK, Martínez-Granado and Ruiz-Castillo (2002) for Spain and Giannelli and Monfardini (2003) for Italy.

However economic constraints are not the only explanations for the different living arrangements. Cultural differences characterizing the relationship between parents and children are also important. Giuliano (2006) starts from the recognition that until the '70s Northern and Southern European countries had similar coresidence patterns, but it changed remarkably afterwards. She tests the hypothesis that the sexual revolution of the '70s had a different impact on living arrangements in Northern and Southern Europe. Due to the closer parent-child ties in the latter countries, after the sexual revolution, Mediterranean youth can live happier in their parents' house, postponing marriage decisions. The test is implemented on a sample of second-generation immigrants in the US in order to disentangle the cultural effects from contemporaneous economic factors (as poor labor or housing market conditions). The set of variables used to identify the effect of Southern European culture has a positive and significant impact on the probability of staying at home.

Manacorda and Moretti provide additional evidence on the cultural differences of Southern European countries using the World Value Survey data and showing that in all countries for both parents and adult children unhappiness is associated with coresidence except in Southern Europe. Parents in Italy and Spain seem to be significantly happier if their children live with them, while the opposite is true in the United States.

Two aspects characterize the specificity of the Southern European countries: the relative stronger family ties than in other countries and the type of welfare state characterized by a familialistic approach with important transfers towards the older generations and very limited direct help towards youth (Ferrera 1996). Whereas weak ties prevail in the Northern part of Europe, strong ties are a particular characteristic of Southern Europe. According to Reher (1998) while in the Northern Europe young adults normally leave their parental households when they have acquired a certain degree of maturity so as to start out their adult lives on their own, in Southern Europe, the process of leaving the parental household tends to coincide more or less closely with their marriage and/or a stable occupation.

Given the weakness of the welfare state, in Southern Europe employment sta- 
tus and parental income play a more relevant role compared to Northern, especially Scandinavian countries (Aassve et al. 2001). The welfare states implicitly or explicitly favors various types of living arrangement (Pezzin et al 2005). Thus, it is difficult to disentangle between the relative importance of these aspects since they are strongly interdependent ${ }^{1}$. A meager welfare state in the South is compensated by strong family ties while a generous one in the North is associated with weak intergenerational ties.

The analysis of the determinants of adult children's coresidence with parents beyond mature age has several important implications. On one hand, the implication of the delay in independence is related to the delay in cohabitation, marriage and fertility with negative effect of birth rate. On the other hand it has important implications on the economic independence of adults children in the labor market. Recent papers examines the interactions between leaving home and entry into poverty: that is, how far poverty entry is the result of leaving home, rather than arising from heterogeneity or selection. Aassve et al. (2006) estimate the effect of home-leaving on entry into poverty and deprivation, with data from the European Community Household Panel (ECHP henceforth). They find that leaving home does have a causal effect on poverty entry, particularly in Scandinavian countries.

The differences across countries allow to investigate further differences in economic constraints, preferences and culture. By means of international comparisons, our research focuses on how the choice of leaving the parental house of adult children depends on personal, family as well as institutional and cultural characteristics; a special emphasis will be given to how they are intertwined with gender differences.

\subsection{Economic Framework}

In this section we briefly describe the economic framework underlying the decision of leaving home that guides the empirical work that follows.

While it is of interest to model children leaving and reentering the household, in this analysis we only consider the initial decision to leave the parents' home. The econometric framework we use can easily be extended to the multiple-spell case, in which residency with the parents is viewed as an alternating renewal process, where a period of living with the parents is followed by a spell of living alone, which may be followed by a return to the parents' house, and so on. Because there is little information about return moves in our data and it is reasonable to think that it is

\footnotetext{
${ }^{1}$ Although Guiso at al. (2006) limiting the analysis to only cultural aspects, like religion and ethnic background, that can be treated as time invariant over an individual's life, show that culture can affect economic outcomes as well as political preferences
} 
not very common, we only focus on the initial move out of the parents' home.

At each time period, the child and her parents determine a value of her staying at the home this period, which includes the option values associated with staying or leaving in future periods. Let this value be denoted $V_{i t}^{H}$ in decision period $t$ for child $i$. In the same way, all parties jointly determine the value of the child leaving in decision period $t, V_{i t}^{L}$, which could include the option value of returning to the parents' home in some point in the future. The home-leaving decision in period $t$ is made by comparing these choice-specific value functions. Define the difference between the two in period $t$ as

$$
D_{i t}=V_{i t}^{H}-V_{i t}^{L}, t=1,2, \ldots
$$

The decision period in which the child actually leaves home is given by

$$
L_{i}^{*}=\min _{t}\left\{D_{i t}<0\right\}
$$

which is interpreted as $L_{i}^{*}$ is the first (decision) time $t$ for which the difference between staying at home and leaving away is negative. In the stochastic process literature, the distribution of $L^{*}$, within or across individuals, is known as a first passage time distribution. In our conceptualization of the model, the first passage time is determined by the distribution of the sequence $\left\{D_{i t}\right\}_{t=1}^{T}$. The determinants of $D_{i t}$ include observed characteristics of the child (and parents), the decision period itself, $t$, and other random variables not explicit in our heuristic derivation.

Our attention, then, is devoted to modeling the first passage time distribution out of the parental home. We use a proportional hazards specifcation of this distribution, in which variables in the aging process part of the $D$ sequence appear in the baseline hazard $\lambda_{0}(t)$, and other observed covariates are included in the function $\phi\left(X_{i t} \beta\right)$.

In our model, the decision of living arrangements of adult children are the outcome not only of personal and household characteristics, but also of variables related to the characteristics of the socio-economic environment the individual and the household face, as well as some cultural proxies.

\section{The statistical model}

In order to estimate the effects of individual's, household+'s and environmental characteristics on the decision to coreside we use a duration model. The econometric specifications of the coresidence decision rule are assumed to be quasi-reduced form representations of the optimization problem. A latent variable structure is assumed. 
Let the net value of co-residence with parent/s for an adult child in period t be given by $L_{i, c, t}$. Define the variable $d_{i, c, t}$ if the adult child cohabits with the parents and 0 otherwise and take the child's age $18 \leq \alpha_{i, c, t} \leq 34$ as a measure of time. Then we have that:

$$
\begin{aligned}
& d_{i, c, t}=1, \text { if } L_{i, c, t} \geq 0 \\
& d_{i, c, t}=0, \text { if } L_{i, c, t}<0
\end{aligned}
$$

We specify a semi-parametric Cox proportional hazard model which defines the instantaneous probability of leaving the state of coresidence, conditional on survival to time $t$, with the hazard function assumed to be as follows:

$$
\lambda\left(t \mid X_{i m, c, t} \beta\right)=\lambda_{0}(t) \phi\left(X^{\prime} \beta\right)
$$

where is the baseline hazard, to which no particular parametrization is given, whereas:

$$
\phi\left(X^{\prime} \beta\right)=\exp \left(H_{i, c, t} \beta_{1}+H H_{i, c, t} \beta_{2}+E_{c, t} \beta_{3}+I_{c, t} \beta_{4}+W_{c} \beta_{5}\right.
$$

In (2) $H_{i, c, t}$ is a row vector containing the observed variables measuring the child i's human capital and gender at time $\mathrm{t}$ in country c; $H H_{i, c, t}$ is a vector of household's characteristics at time $\mathrm{t}$ in country $\mathrm{c}$ and it includes variables such as the number of siblings as well as the presence of grandparents, parents' education and the mother working status ${ }^{2} . E_{c, t}$ is a set of variables describing the socio-economic environment (labor market characteristics, marriage market, the degree of financial market development as proxied by the down payment ratio). The vector $E_{c, t}$ varies across countries and years, but is constant for all individuals surveyed in a particular year and country. The fourth group of vectors is given by $I_{c, t}$ and $W_{c}$. The first one varying by country $\mathrm{c}$ and time $\mathrm{t}$ contains the youth social policy expenditure in percent of total public expenditure and the proportion of the World Value sample aged from 35 to 70 that declared independence as an important child quality. Finally the $W_{c}$ vector is a set of dummy variables, controlling for the four groups of countries.

In this model we use both individual data and data at regional and country level to describe the environment adult children face. Since observations are not i.i.d, due to geographical and temporal clustering we account for be seriously biased downward. The bias of the standard errors can result in spurious findings of statistical

\footnotetext{
${ }^{2}$ We restrict the analysis to the sample of those that were coresiding at least for one wave and follow them until they become an independent family unit.
} 
significance for the aggregate variable of interest (Moulton, 1990). We correct this bias by "clustering" the observations by individual and alternatively by region ${ }^{3}$.

Under the assumption that all regressors might have a different impact on the living arrangement choice depending on the child's gender, we then estimate separately the same model for males and females $m$ and $f$ :

$$
\begin{gathered}
\lambda\left(t \mid X_{i m, c, t}^{\prime} \alpha\right)=\lambda_{0}(t) \exp \left(H_{i, c, t} \alpha_{1}+H H_{i, c, t} \alpha_{2}+E_{c, t} \alpha_{3}+I_{c, t} \alpha_{4}+W_{c} \alpha_{5}\right) \\
\lambda\left(t \mid X_{i m, c, t}^{\prime} \delta\right)=\lambda_{0}(t) \exp \left(H_{i, c, t} \delta_{1}+H H_{i, c, t} \delta_{2}+E_{c, t} \delta_{3}+I_{c, t} \delta_{4}+W_{c} \delta_{5}\right)
\end{gathered}
$$

In particular, we are interested in comparing the coefficients of parental characteristics, labor and marriage markets, financial markets imperfections as well as welfare state and social values obtained from the two specifications, in order to disentangle how each of them interplay with gender differences.

Finally, as a sensitivity analysis, for each group of country $W_{c}$, we estimate the following model:

$$
\lambda\left(t \mid X_{i m, c, t}^{\prime} \gamma\right)=\lambda_{0}(t) \exp \left(H_{i, c, t 1} \gamma+H H_{i, c, t} \gamma_{2}+E_{c, t} \gamma_{3}+I_{c, t} \gamma_{4}+C_{c} \gamma_{5}\right)
$$

where the vector $\mathrm{C}$ is a set of country dummy variables

We will estimate the model using the partial likelihod function for the Cox estimator (1975) which allow to estimate the parameters without requiring simultaneous estimation of the baseline hazard function $\lambda_{0}(t)$. Let $t_{1}<t_{2} \ldots .<t j$ are the ages at which you observe children leaving home, in our case $t_{1}=$ age -18 , assuming that 18 is the earliest age in which children leave home. In our sample:

$t_{1}=1, t_{2}=2, \ldots t_{16}=J=16$, given that our sample is $18-34$

$R\left(t_{i}\right)$ : all people who haven't exit by age $t_{j}$ is the risk set defined all the individuals $D\left(t_{i}\right)$ indices of individuals exiting at age i set of spells complete at $t j$

Then the partial likelihood is given by the joint product :

$$
L p(\beta)=\prod_{j=j}^{J} \frac{\prod_{m \in D\left(t_{j}\right)} \phi\left(X_{m}^{\prime} \beta\right)}{\sum_{l \in R\left(t_{j}\right)} \phi\left(X_{l}^{\prime} \beta\right)}
$$

\footnotetext{
${ }^{3}$ Results from the latter case are not reported as they are similar to the ones reported below, but can be distributed by the authors upon request.
} 
The estimation of $\beta$ is obtained by minimizing the log partial likelihhod function $\ln L p$. The partial likelihood is a limited information likelihod given that the baseline hazard $\lambda_{0}(t)$ has dropped out. However, though $\ln L p$ is not the full likelihood functio, the estimator of $\beta$ that maximizes the $\ln L p$ has been shown to be consistent (Andersen et al 1993).

\section{Data description}

In our empirical analysis we use the ECHP, a longitudinal survey coordinated and supported by EUROSTAT. The survey involves a representative sample of households and individuals interviewed for eight years (1994-2001) in each of the 15 European countries (Austria (from 1995), Belgium, Denmark, Finland (from 1996), France, Germany, Greece, Italy, Ireland, Luxembourg (1995), the Netherlands, Portugal, Spain, Sweden (from 1996) and U.K).

The standardized methodology and procedure in data collection yield comparable information across countries, making the ECHP a unique source of information for cross-countries analyses at the European level. The aim of the survey, in fact, is to provide comparable information on EU population, representative both at the longitudinal and the crosswise level. The data collected cover a wide range of topics on living conditions (income, employment, poverty and social exclusion, housing, health, migration, and other social indicators).

The unit of analysis of the ECHP are the family and, within the households, all individuals older than 16, even if it is possible to retrieve information (mainly demographic information) also on children under 16. The ECHP has many advantages: it covers the whole population, including non-working persons; as a household data set, it includes a lot of useful and harmonized information (for example number and age of children, or marital status). Moreover, it is possible to link household-level information to individual data so that it allows to study, for instance, the labor supply decisions of an adult child accounting for his/her own personal characteristics but also for those of co-resident parents.

For our empirical analysis we selected fourteen countries of the dataset, representative of the different geographical areas of Europe ${ }^{4}$. For the fourteen countries we consider all available waves, creating an unbalanced panel. We also selected all households in which adult children are in the age range 18-34. The sample size is made of 33,153 individuals repeated between 2 and 8 times, with a total of 143,492 observations.

\footnotetext{
${ }^{4}$ We excluded Sweden as it was designed as a cross- sectional sample.
} 
We combine them in four groups: Northern non-continental countries (the U.K. and Ireland), Northern Continental countries (Denmark and Finland), Central-Western countries (Austria, Belgium, France, Germany, Luxembourg and the Netherlands) and Southern countries (Italy, Greece, Portugal and Spain). The four groups of European countries identify not only geographical contiguity, but also similar culture as well as alike welfare states.

Figure 2 contains the coresidence age profiles computed by the Kaplan Meier survival function showing differences across countries and homogeneity within. The two most homogenous groups are the Scandinavian countries and the Southern countries. In Denmark and Finland, children leave the household between 18 and 22 and after that age a very negligible proportion still cohabit with their parents. At the opposite side of the spectrum, in the Southern countries, a very limited proportion leave the household before the age of 22 and more than 50 percent is still there until 30.

Figure 3 illustrates gender differences in all countries, showing a similar coresidence pattern: women leave parental house at a younger age than men. Differences are larger in Greece and Italy, consistent with the fact that women leave home earlier than men in part because they marry and marry younger than men.

Table 1 shows the temporal pattern of coresidence rates and the sample size by country. While in Austria. Belgium, Greece, Ireland we see a remarkable growth in the period we consider, in Luxembourg, Denmark, Finland, Portugal and Spain the coresidence rates decline.

The distributions by educational groups and gender reported in Table 2 show further discrepancies across countries. While in Italy, Ireland, Greece, Austria and Belgium a greater proportion of young adults has a second level of education relatively to the primary, in Portugal Spain, the UK and Denmark the proportion is larger among youth with less than secondary level. In countries as Belgium, Denmark, France and Ireland a non negligible proportion of men and women is still studying varying from 10 to 30 percent, in most the percentage is not worth to be considered and above all in countries like Spain, Austria and Italy it is below 0.5. In all countries, except for Germany and Luxembourg, the percentage of co-resident women with a college degree is relatively higher than the one for young men.

The independent variables we use to explain adult children decision can be divided in four main groups. The first type regards personal characteristics: adult children's age, adult children's gender and a dummy variable controlling for third educational level (college degree and further).

The second group includes household's characteristics: i.e. number of siblings living in the household, presence of grandparents, mother's education and father's education (defined as for the children) and mother's working status (dummy vari- 
able).

The information given by the ECHP dataset has been also augmented with additional information taken from various statistical sources. They are referred to as the third group of regressors. In particular, we consider a labor market indicator, computed on the basis of annual female and male unemployment rates defined at the regional level and a proxy for the local marriage market, i.e. the local sex ratio computed as the ratio between female population over total population with child's same age band living in the same region ${ }^{5}$ (they both are computed from the EUROSTAT REGIO dataset, years 1994-2001). We also examine the loan to value ratio, which measures the availability of mortgage finance by country: it refers to conventional home-purchase loans to first-time buyers. Even though the loan to value ratio might have changed during a decade, we consider the average values for two decades, i.e. the 90s and 2000s as reported in Chiuri and Jappelli (2003) and in Maclennan et al. (1998). The country average values for the three indicators are reported in Table 3 , columns 1-3.

The forth set of variables controls for welfare states type and cultural contiguities. While following the standard time invariant grouping of the countries considered (Esping Andersen 1999) mimicking (not only) the various welfare state types, we also consider an alternative and time varying measure of the country welfare state. In particular, we include the annual youth social expenditures as percentage of total public expenditure, computed on the basis of the OECD SOCX $(2006)^{6}$. This proxy shows that Southern European welfare states are less oriented towards helping young people in starting out and being economically independent compared to Scandinavian countries.

Finally, in order to find key indicators capturing cross country differences of social values, we use the World Values Survey, which periodically collects information regarding individuals' opinion and family attitudes since 1981, based on a representative sample of the whole population. We look at the percentage of the sample aged from 35 to 70 that answered positively to the following question: "Here is a list of qualities that children can be encouraged to learn at home. Which if any do you consider to be really important: independence?" and we use it as an indicator of the relative importance of children's independence as social value in a country (see Table 3 column 5). We select two waves (1990 and 2000) as we need both crosssectional and cross-temporal evidence on family attitudes to disentangle the role of social perception from other specific country effects.

\footnotetext{
${ }^{5}$ If the child is a woman, the sex ratio is computed as the proportion of male population over total population with her age band and living in the same country region.

${ }^{6}$ See note in Table 3 for a definition.
} 
However, we should reckon that welfare regimes are deeply intertwined with culture. As such they both cannot be taken as purely exogenous. Although potentially relevant, we prefer not to analyze explicitly this issue, but to leave it for future work.

As a preliminary evidence we report results from a univariate analysis. Figure 4 plots the average co-residence rate by country against the loan to value ratio (LTV). The size of the co-residence rate correlates negatively with the loan to value ratio, that is countries with deepest mortgage markets are also those that features the lowest coresidence level.

Figure 5 shows that in countries more oriented towards helping young people in starting out and being economically independent, youth social expenditures (as percentage of total public expenditure) are higher and the proportion of children living with their parents is smaller.

The World Values Survey data show that in Southern European countries a smaller proportion of individuals report that independence is an important child quality. Figure 6 and 7 show that the smaller is the proportion of individuals aged from 35 to 70 valuing independence by country, the greater the number of individuals aged 18-34, distinct by gender, living with their parents.

\subsection{Empirical results}

Table 4 contains results of three different models. Coefficients are reported as hazard ratios - i.e. as exponentiated coefficients- rather than as coefficients themselves; standard errors are computed by delta method.

In Model 1 (Column 1), we estimate the impact of personal and household characteristics (gender, household composition, personal and family members education and mother working status). The estimates regarding children's gender show that being a young man results in a lower hazard - and therefore a longer survivor time in co-residence- than young women. The faily size appears also to have an important impact. The higher is the number of siblings the shorter is the time of coresidence. Parental education (proxy for permanent income) is also important. In households where mothers and fathers have a higher education it is less likely that adult children co-reside. This interpretation here is twofolds: in higher educated households potentially greater resources are available to the household which allow children to move out earlier and a greater value attached on children independence.

We also include the occupational status of the mother. This variable can be interpreted on one hand as additional income which increases the resources to the household, it potentially increases family resources which can be used to subsidize children in their choice of living independently McElroy's (1985) and Diaz Guillo 
(2005). From a working mother point of view, in fact, it may be less important whether the child stays at home or not given that she does not share a lot of time with them. This would imply a positive impact on children desire of independence. A similar implication would derive from a cultural interpretation. In fact according to recent research, it can be also interpreted as a proxy for family culture of women's independence (Del Boca, Locatelli and Pasqua 2000, Fernandez et al 2005, Giuliano 2006).

On the other hand, these resources can be used to supply larger space and support in the parental house for children prolonging their coresidence (in order to finish schooling or achieve their preferred position in the labor market). The coefficient is mother's work seems to support the former view against the latter. However, given the contemporaneous relationship, there is an issue of endogeneity that has to be taken into account. In this explorative and descriptive nature of the present research we do not deal with this issue now.

The presence of grandparents delays the search for independence confirming early results of potential need of coresidence of adult children in order to help taking care of the elderly (Pezzin et al. 2006).

We now turn to discuss the impact of marriage and labor markets characteristics, as well as the degree of mortgage market imperfection (Model 2). The sex ratio (indicator of the probability of finding a partner in a given area) has a positive and significant effect on the hazard function, indicating that, conditional on other characteristics, the marriage market provides a strong alternative to coresidence. In regions with higher unemployment rate the proportional change in hazard is lower (confirming earlier results of Card and Lemieux, 2000, and Rosenzweig and Wolpin, 1993 and Becker, Bentolila, Fernandes and Ichino, 2005). The downpayment ratio also significantly decreases the risk of switching to other living arrangements. This evidence is supportive of the view that mortgage market imperfections affect the choice of coresidence of adult children with parents (Martins and Villanueva, 2006).

Finally (in Model 3), we include the proxies for the welfare states and culture. The results show that higher levels of public expenditure devoted to the youth increase the proportional change in hazard rate, inducing a shorter stay in parental home. The proxy we use for culture is here ineffective. The significance of some of the Wc dummy variables indicates that there are further institutional differences not captured by the set of indicators selected. In particular, we find that living in Northern Continental or Central West countries relatively to Southern countries significantly increases the proportional change in the hazard rate.

Given the significance of the gender coefficient we now turn to estimate separately their survival experience. This exercise is also driven by results from the log rank test 
for equality of survivor functions: the statistic computed $((1)=40.63)$ rejects the null that the survivor functions of the two groups are the same. Table 5 reports the coefficients of the specification (3) and (4) for males and females, respectively. The coefficients related to number of siblings and presence of grandparents have similar signs in the two specifications, but they are larger in magnitude for females.

Parents education (proxy for income) induces a more effective search for independence and are significant only for men. This is coherent with previous research which reports the lower significance of parents resources on females coresidence rates (Aasve et al. 2001).

Mother's work coefficients are significant in both, even the value is slightly larger for females. In this respect, the coefficient can also be interpreted as a proxy for family culture of women 's independence which coherently is greater for women than for men.

While the coefficients related variables related to the labor market and to the mortgage market are almost identical for males and females, the impact of the marriage market has a slightly greater for women. For women, marriage is still one of the most important reasons to leave the parental home and tend to marry younger than men especially in Southern countries.

Although we find that the measure of youth social expenditure has a relatively stronger impact for women than for men, we instead ascertain that our indicator of social values for independence has a significantly stronger effect on the male hazard function than the female one, delaying their timing for independence.

The differences in the coefficients of Northern and Central countries relatively to the South are statistically significant both for males and females which may be interpreted with differences across groups of countries in strength of family ties as well as in the welfare states.

Finally, as a sensitivity analysis, Table 6 reports results from the estimation of equation (5) by group of countries, controlling for single country fixed effects. Although most regressors confirm previous results, some of them shows a bigger and sometimes different impact in some group of countries compared to others. In particular, higher child's education significantly results in a longer survivor time in co-residence in Northern continental countries; mother working status significantly lowers the timing of coresidence except for Northern non continental countries, where mother additional income allows children to achieve a better position before leaving the nest. The presence of grand parents is relevant only in Central Western and in Mediterranean countries, where stronger family ties are present. The sex ratio, implicitly the marriage market, is most relevant in the Mediterranean countries. Social values for children independence increases the proportional hazard function only 
in Central West countries, whereas the significance in all country dummies, except for the one controlling for Denmark in the group of Northern Continental countries, shows further differences across countries not captured by previous regressors.

\section{Conclusion}

In this paper we provide an explorative analysis attempting to interpret the very complex phenomenon of co-residence behavior of adult children with their family. We have explored the relevance of several factors including age, gender, education, family structure and institutional characteristics.

Parents' characteristics are also important. Mothers and fathers who have a higher education are less likely to have adult children cohabiting (increasing the resources which allows children to move out), and the occupational status of the mother which has a similar effect. This variable can be interpreted not only as additional income which increases the resources to the household, but also as a proxy for family culture of women's independence. While parents education are significant only for males, the coefficients related to mother's work are instead slightly larger for females.

The presence of grandparents in the household while significant in both equations has a larger and negative coefficient in women hazard equation indicating a persistence of traditional role.

While the variables related to the labor market is almost identical for males and females, the impact of the marriage market has different signs and magnitude. The marriage market increases the proportional hazard change in living arrangements for women. For women marriage is still one of the most important reasons to leave the parental home and tend to marry younger than men especially in Southern countries.

Gender differences appear then to be an important aspect (both in the parents education and on the different response to marriage market conditions as well as the different welfare states) and need to be further explored.

Finally the greater coefficient of Northern and Central countries relatively to the South implies that the differences across countries results show that poor labor market conditions and meager social policies are important constraints in the decisions of young adults of leaving home. The analysis of the determinants of adult children's coresidence with parents beyond mature age is a crucial problem in Mediterranean countries with several important implications on the delay in cohabitation, marriage and fertility. Our results, though descriptive in nature, can be useful for informing policy makers regarding the importance crucial reforms in the area of the labor 
market as well as the housing market in order to make the transition to indipendent living arrangements easier for adult children in Mediterranean countries. 


\section{References}

[1] Aassve, A., F.C. Billari, S. Mazzuco, F. Ongaro (2002) "Leaving Home: A Comparative Analysis of ECHP Data", Journal of European Social Policy, 12, 4: $259-276$

[2] Aassve, A, M. Iacovou (2006) "Youth Poverty and Transition to Adulthood in Europe". Demographic Research, 15, pp 21-40, July.

[3] Aassve, A., M. A. Davia, M. Iacovou, S. Mazzuco (2006) 'Does Leaving Home Make You Poor? Evidence from 13 European Countries'. Working Paper of Institute for Social and Economic Research, paper 2005-24. Colchester: University of Essex, September.

[4] Becker S., S. Bentolila, A. Fernandes and A. Ichino (2005) "Youth Emancipation and Perceived Job Insecurity of Parents and Children" IZA D.P. 1836, Bonn.

[5] Cantó-Sánchez O. and M. Mercader-Prats (1996) "The impact of Youth Dependency and Employment on Household Poverty: Evidence from Spain", Spain.

[6] Card D. and T. Lemieux (2000) "Adapting to Circumstance: The evolution of Work, School and Living Arrangements Among North American Youth", in Blanchflower D. and R. Freeman (eds.) Youth Employment and Joblessness in Advanced Countries, University of Chicago Press.

[7] Chiuri, M. C., and T. Jappelli (2003), "Financial Market Imperfections and Home Ownership: a Comparative Study." European Economic Review 47, 857875 .

[8] Dalla Zuanna, G., Micheli, G. A. (2004), "Introduction", in Dalla Zuanna, G., Micheli, .(eds.), Strong Family and Low Fertility: A Paradox?, Kluwer Academic Publishers, Dordrecht / Boston / London.

[9] Del Boca D., M. Locatelli and S. Pasqua (2000) "Employment Decisions of Married Women: Evidence and Explanations", Labour 14, 3, 40-52

[10] Diaz A. and Guillo M.D. (2005) "Family ties and labour supply" Investigationes Econòmicas, XXIX, (2): 289-329.

[11] Ermisch J. (1999) "Prices, parents and young people's household formation", Journal of Urban Economics, 42:1-17. 
[12] Esping-Andersen G., (1999), Social foundations of postindustrial economies, Oxford University Press, Oxford.

[13] Farrè L. and F. Vella (2007) "The Intergenerational Trasmission of Gender Role Attitudes and its Implications for Female Labor Force Participation", IZA DP no. 2802, May, Bonn.

[14] Fernandez R., A. Fogli and C. Olivetti (2005) "Mothers and Sons: Preference Formation and Female Labor Force Dynamics", The Quarterly Journal of Economics, MIT Press 119(4): 1249-1299

[15] Ferrera, M. (1996), "The Southern Model of Welfare in Social Europe", Journal of European Social Policy, 6, 179-89.

[16] Fogli A. (2004) "Endogenous Labour Market Rigidities and Family Ties", mimeo, New York University.

[17] Fortin N. M. (2005) "Gender role attitudes and the labor- market outcomes of women across OECD countries" Oxford Review of Economic Policy, 21 (3): 416438.

[18] Giannelli G. and C. Monfardini (2003) "Joint decisions on household membership and human capital accumulation of youths. The role of expected earnings and local markets", Journal of Population Economics, May, 16 (2): 265-285.

[19] Giuliano P. (2006) "Living Arrangements in Western Europe: Does Cultural Origin Matter?" IZA Working Paper no. 2042, March.

[20] Guiso L., P. Sapienza and L. Zingales (2006) "Does Culture affect Economic Outcomes?", The Journal of Economic Pespectives, 20 (2), spring.

[21] Locatelli M., V. Moscato and S. Pasqua (2001) "The European Community Household Panel (ECHP): Elements for Users with Special Focus on Labor and Household Economics", CHILD Working Paper no. 2001-24.

[22] Maclennan D., Muellbauer, J., Stephens, M., (1998). "Asymmetries in housing and financial market institutions and EMU". Oxford Review of Economic Policy, 14 (3): 54-80.

[23] Manacorda M. and E. Moretti (2007) "Why do most Italian Young Men live with Their Parents? Intergenerational Transfers and Household Structure", Journal of the European Economic Association. 
[24] Martínez-Granado M. and J. Ruiz-Castillo (2002) "The decisions of Spanish youth: A cross-section study", Journal of Population Economics, 15 (2), May: 305-330.

[25] Martins N. and E. Villanueva (2006) "Does Limited Access to Mortgage Debt Explain Why Young Adults Live with their Parents?" February, Banco de España Working Paper no. 0628, Spain.

[26] McElroy M. (1985) "The Joint Determination of Household Membership and Market Work: The Case of Young Men", Journal of Labor Economics, 3 (3): 293- 316.

[27] Pezzin, L.E., R.A. Pollak, and B.S. Schone (2005), "Efficiency in Family: living arrangements and caregiving decisions of adult children and elderly parents", in Long Term care and Family Decision Making: Coresidence and Efficiency, mimeo.

[28] Reher D. S. (1998) "Family Ties in Western Europe Persistent Contrast" Population and Development Review vol 24 n.2 (Jun 1998) pp 203-234

[29] Rosenzweig M. and K. Wolpin (1993) "Intergenerational Support and the LifeCycle Incomes of Young Men and Their Parents: Human Capital Investments, Coresidence, and Intergenerational Financial Transfers" Journal of Labor Economics, 11 (1): 84- 112. 


\section{Figure 1}

Individual countries co-residence rates in $\mathbf{2 0 0 1}$

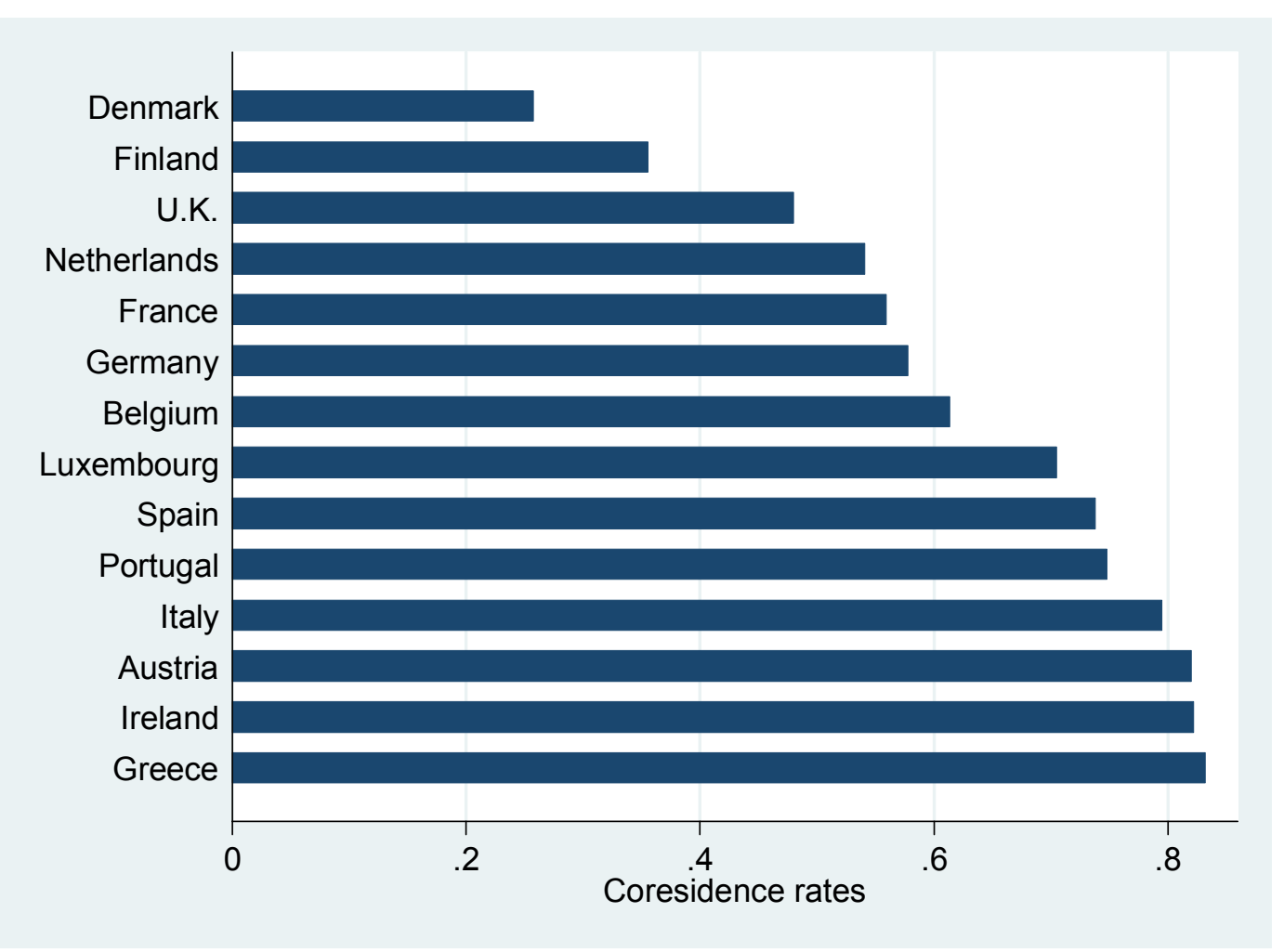

Source: ECHP $20018^{\text {th }}$ Wave. 


\section{Figure 2}

\section{Individual countries co-residence profiles}
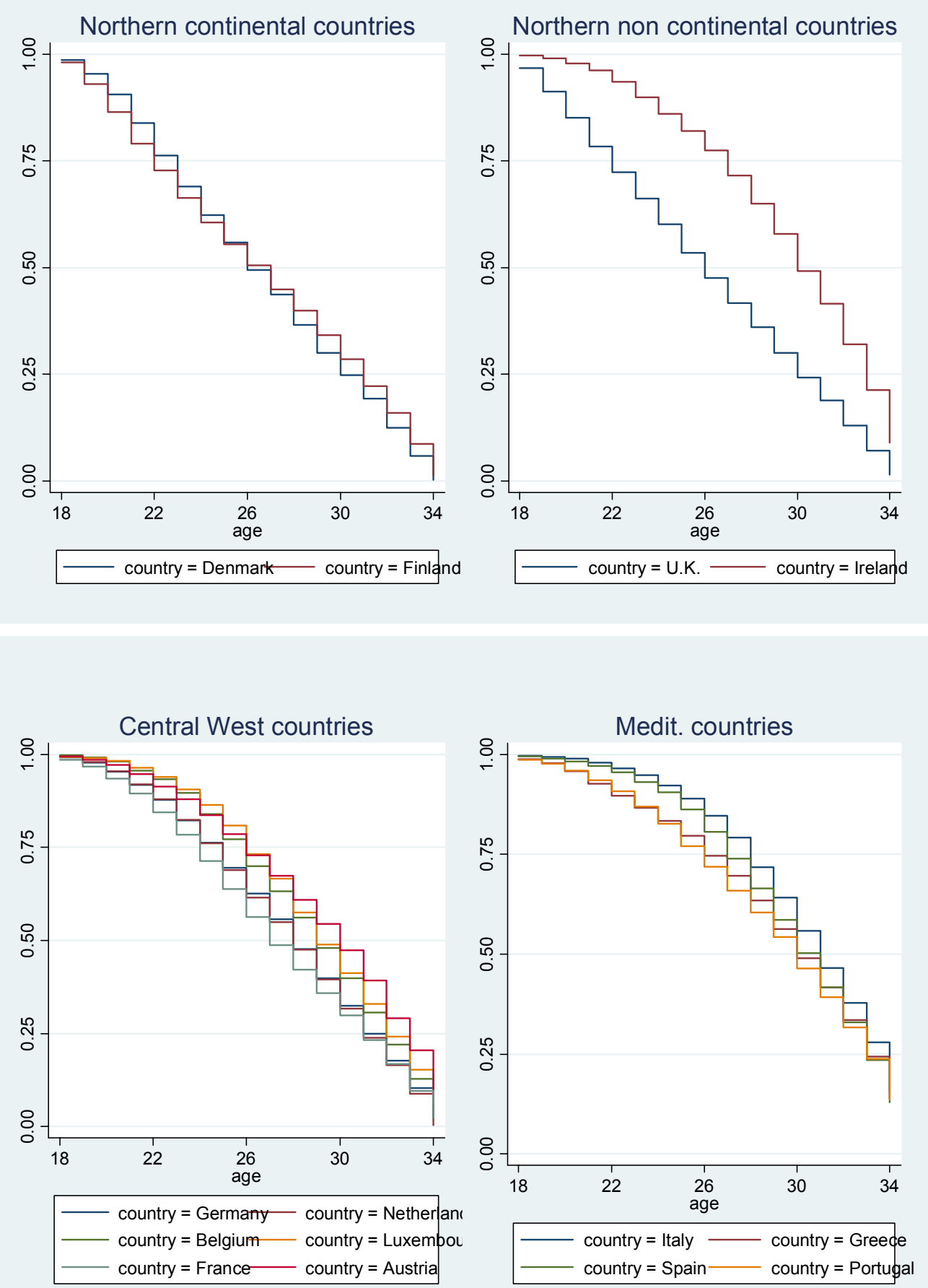

Note: The figure reports the Kaplan Meier survival estimates by 14 ECHP countries, grouped by geographical and cultural contiguities. 


\section{Figure 3}

\section{Individual countries co-residence profiles: gender differences}
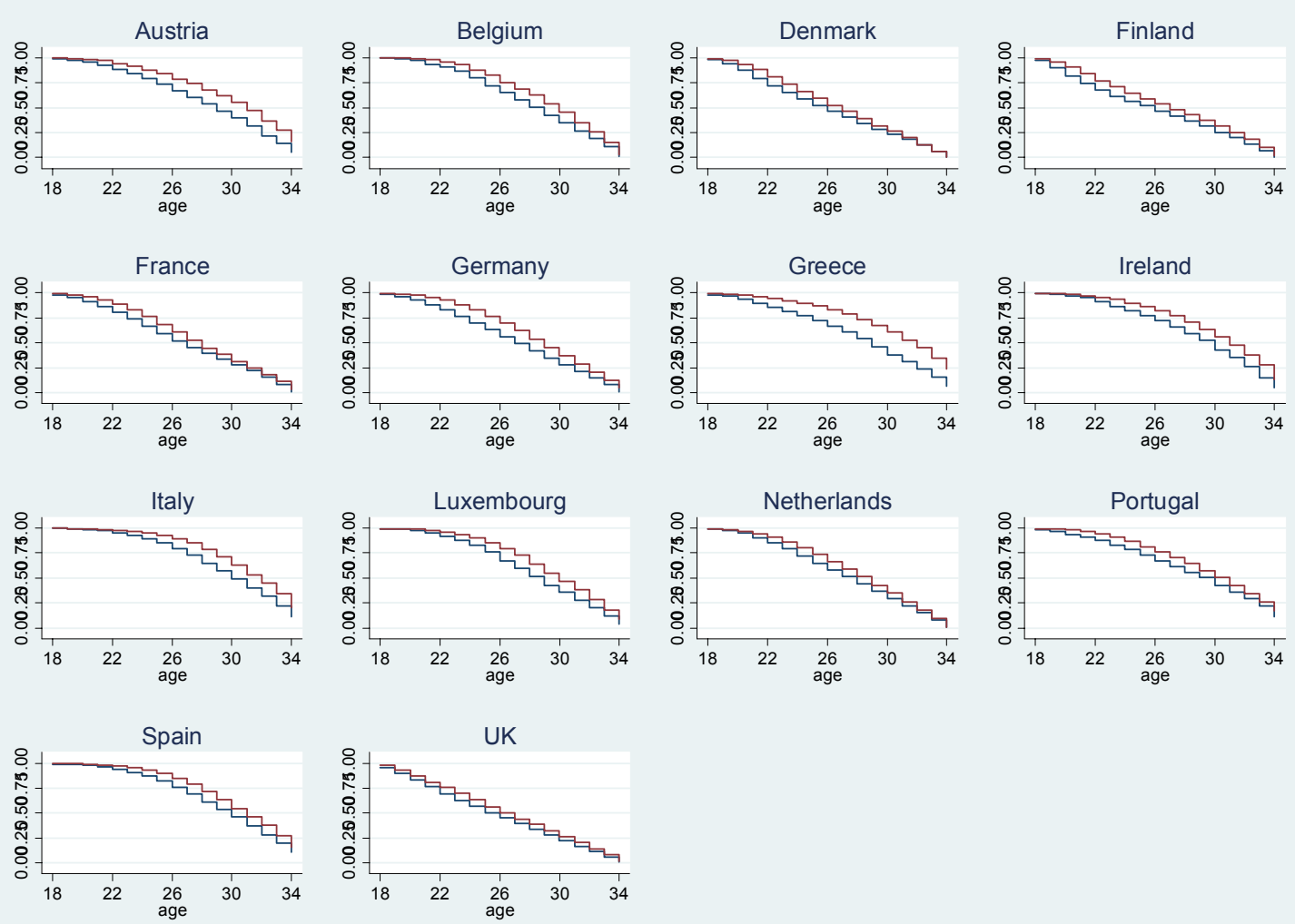

Note: Each graph contains the Kaplan Meier survival estimates by gender. The blue line describes women's survival function by age; the red line follows men's one. 


\section{Figure 4}

Average co-residence rate by country and maximum loan to value ratio

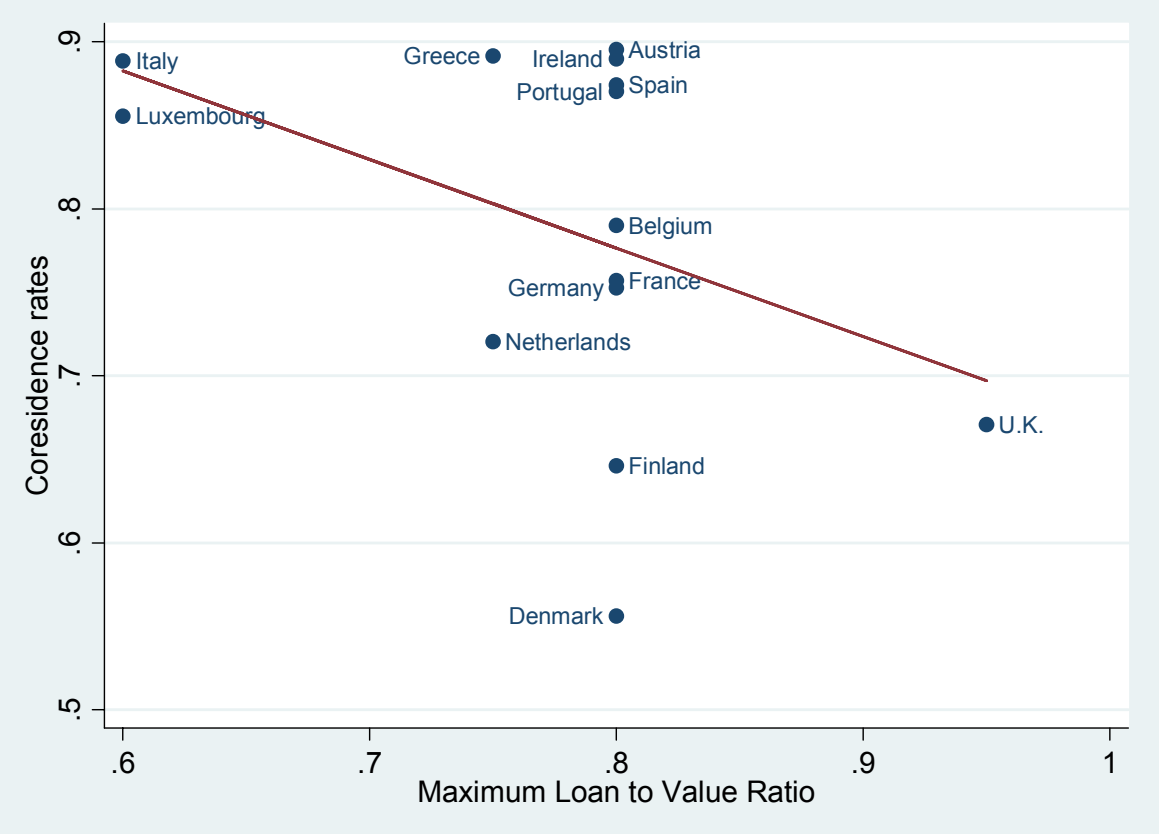

Sources: ECHP all waves and Maximum LTV ratio taken from Chiuri and Jappelli (2003).

\section{Figure 5}

Average co-residence rate by country and youth social expenditure as percentage of total public expenditure

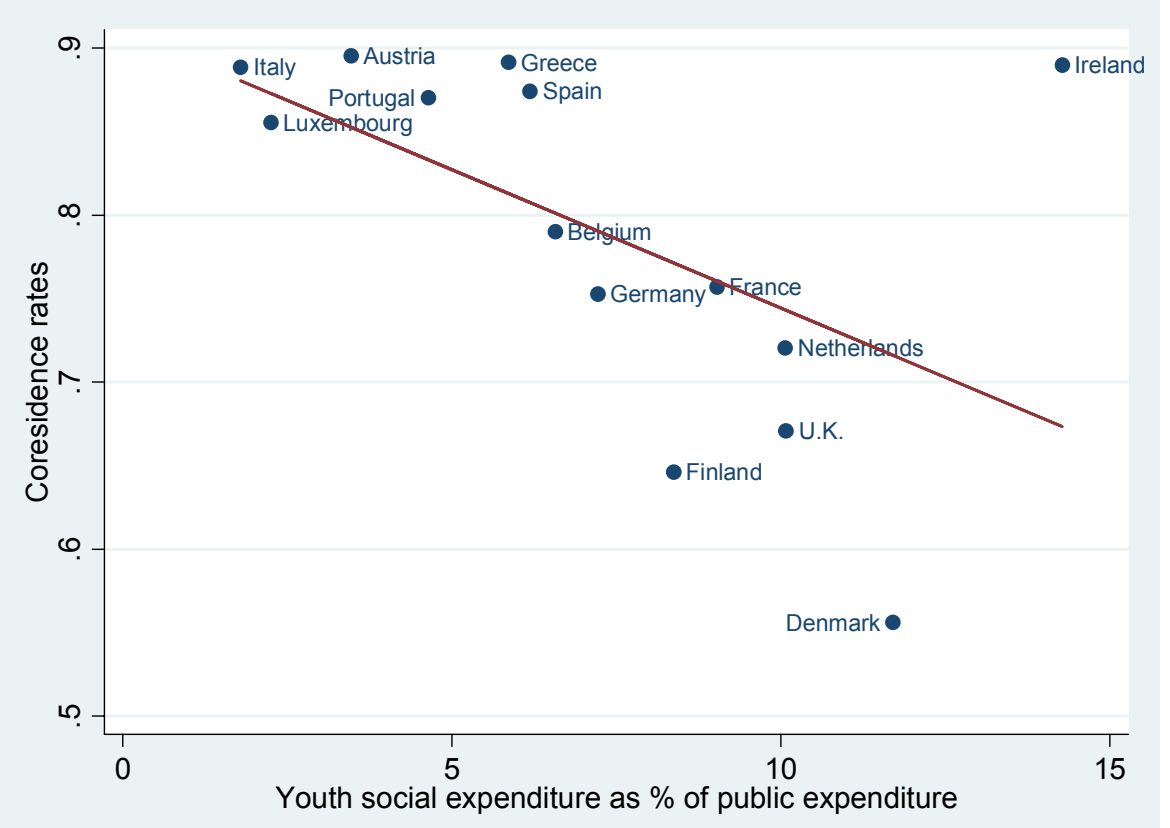

Sources: ECHP all waves and OECD SOCX database (averages 1994-2001) 


\section{Figure 6}

Men co-residence rates and independence as an important child quality for parents

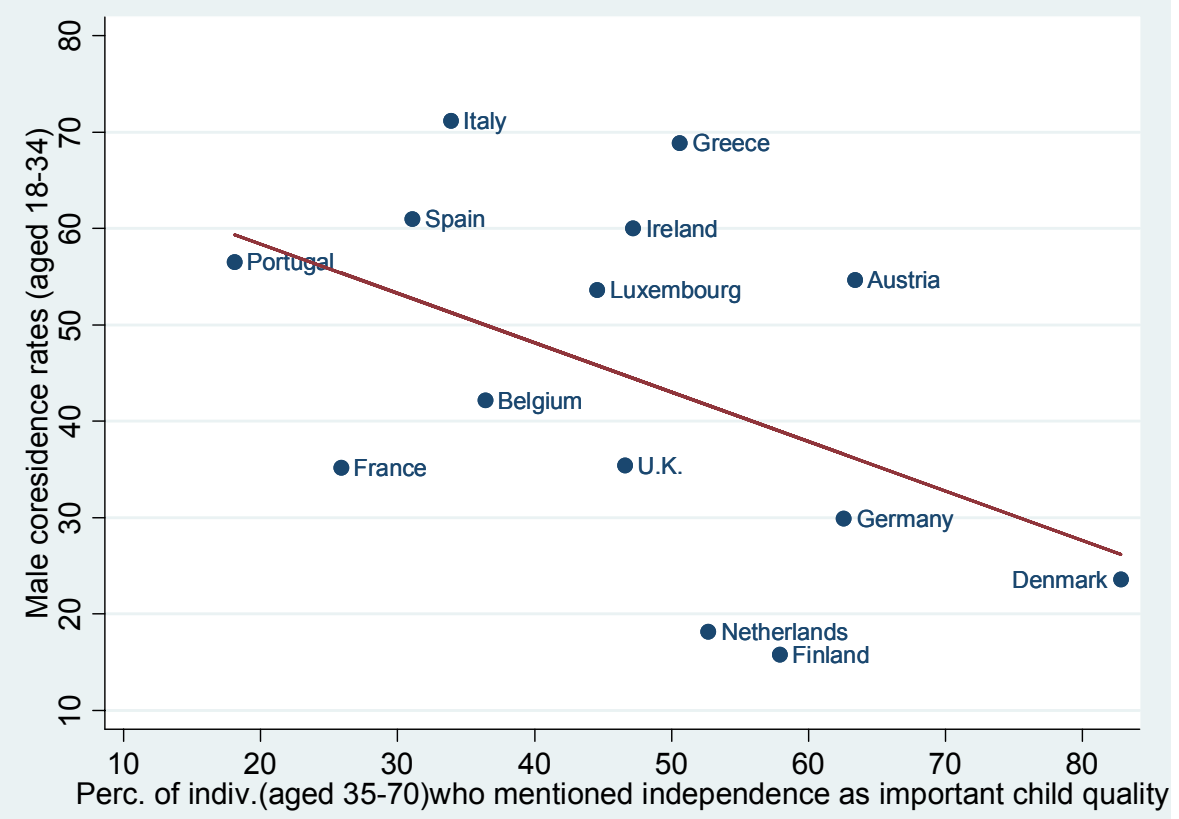

Source: World Value Survey (waves 1990-2000)

\section{Figure 7}

Women co-residence rates and independence as an important child quality for parents

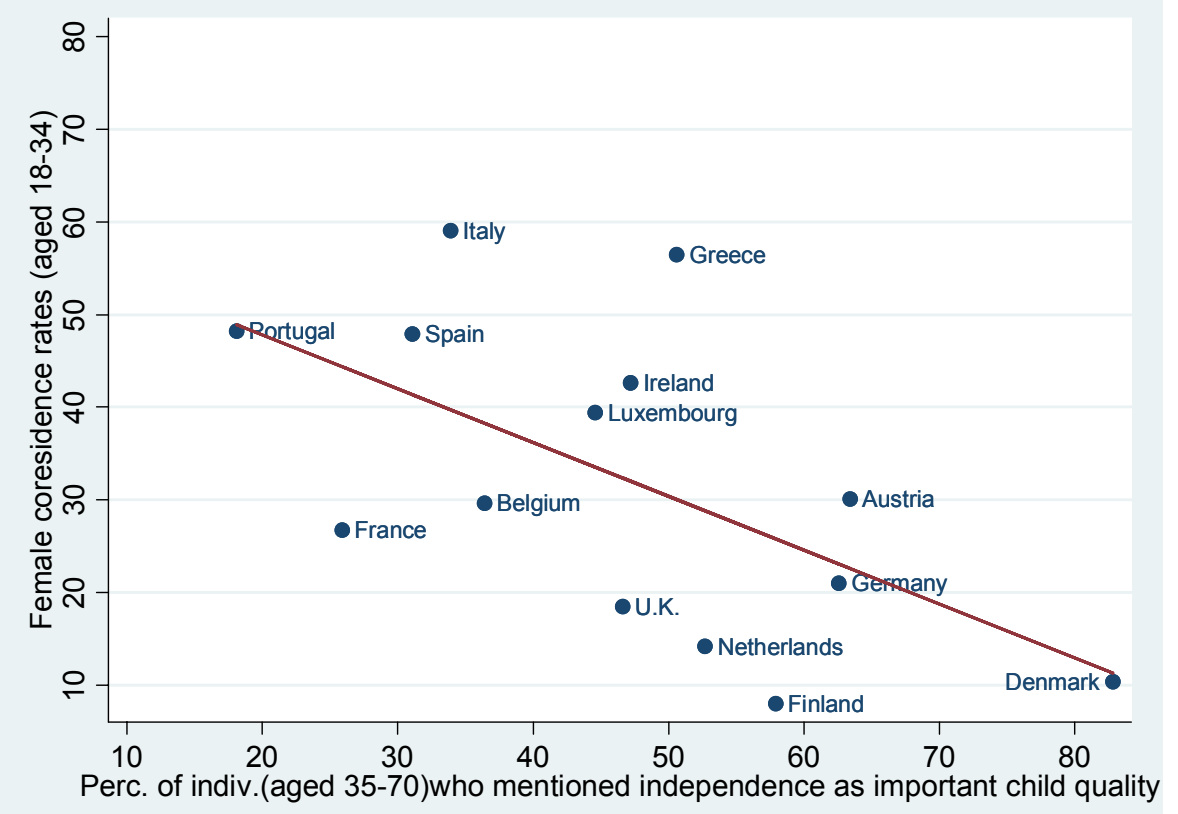

Source: World Value Survey (waves 1990-2000) 
Table 1

Individual aged 18-34 living in the parental home by country and wave (in percent and total sample)

\begin{tabular}{c|cccccccccccccc}
\hline \hline Wave & $\mathbf{A u}$ & $\mathbf{B e}$ & $\mathbf{D k}$ & $\mathbf{F i}$ & $\mathbf{F r}$ & $\mathbf{G e}$ & $\mathbf{G r}$ & $\mathbf{I r}$ & $\mathbf{I t}$ & $\mathbf{L u}$ & $\mathbf{N l}$ & Po & Sp & Uk \\
\hline 1994 & - & 36.2 & 19.3 & - & 35.6 & 33.4 & 49.8 & 65.3 & 66.5 & - & 24.9 & 62.4 & 63.8 & 24.8 \\
Total & - & 2,064 & 1,751 & - & 4,507 & 4,358 & 3,556 & 3,383 & 5,629 & - & 2,853 & 2,986 & 5,703 & 3,127 \\
1995 & 46.6 & 38.0 & 18.3 & - & 37.4 & 32.3 & 55.7 & 62.7 & 68.1 & 54.6 & 24.3 & 65.3 & 64.8 & 24.3 \\
Total & 1,887 & 1,915 & 1,670 & - & 4,249 & 4,431 & 3,649 & 2,838 & 5,396 & 1,884 & 2,735 & 2,870 & 5,393 & 3,001 \\
1996 & 48.2 & 39.2 & 19.0 & 36.9 & 37.8 & 32.6 & 58.4 & 61.9 & 67.2 & 54.0 & 24.5 & 62.0 & 64.8 & 25.7 \\
Total & 1,838 & 1,774 & 1,513 & 2,274 & 4,130 & 4,253 & 3,437 & 2,474 & 5,449 & 1,599 & 2,681 & 3,014 & 5,210 & 3,038 \\
1997 & 48.6 & 39.1 & 18.1 & 35.9 & 37.4 & 32.8 & 58.8 & 61.2 & 66.5 & 44.9 & 25.3 & 62.1 & 65.0 & 26.6 \\
Total & 1,753 & 1,615 & 1,409 & 2,227 & 3,853 & 4,072 & 3,216 & 2,249 & 5,127 & 1,826 & 2,567 & 3,082 & 4,931 & 2,975 \\
1998 & 49.6 & 39.4 & 15.8 & 29.9 & 35.6 & 33.3 & 60.8 & 62.0 & 63.5 & 43.6 & 23.1 & 60.7 & 63.5 & 27.0 \\
Total & 1,635 & 1,453 & 1,278 & 2,176 & 3,523 & 3,833 & 2,865 & 2,047 & 4,980 & 1,634 & 2,415 & 3,089 & 4,593 & 2,927 \\
1999 & 52.8 & 40.0 & 14.2 & 27.1 & 36.1 & 33.6 & 62.3 & 65.9 & 63.8 & 37.7 & 24.9 & 59.5 & 61.7 & 26.9 \\
Total & 1,566 & 1,316 & 1,169 & 2,071 & 3,301 & 3,668 & 2,759 & 1,678 & 4,767 & 1,678 & 2,305 & 3,079 & 4,325 & 2,808 \\
2000 & 53.6 & 41.4 & 15.7 & 22.7 & 34.7 & 34.2 & 63.7 & 68.8 & 63.8 & 37.6 & 25.2 & 57.9 & 59.3 & 26.5 \\
Total & 1,427 & 1,192 & 1,122 & 1,766 & 3,090 & 3,443 & 2,714 & 1,364 & 4,470 & 1,472 & 2,312 & 3,108 & 4,015 & 2,683 \\
2001 & 55.3 & 41.8 & 13.9 & 22.4 & 36.0 & 35.1 & 65.6 & 70.3 & 64.7 & 34.2 & 26.5 & 56.0 & 57.8 & 26.5 \\
Total & 1,370 & 1,049 & 1,043 & 1,798 & 3,006 & 3,202 & 2,703 & 1,222 & 4,050 & 1,528 & 2,170 & 3,087 & 3,868 & 2,604 \\
\hline Sour
\end{tabular}

Source: ECHP waves 1-8

Table 2

Adult children (individuals aged 18-34) living in the parental home by country, gender and educational level (in percent)

\begin{tabular}{|c|c|c|c|c|c|c|c|c|c|c|c|c|c|c|c|}
\hline & Education & $\mathbf{A u}$ & Be & Dk & $\mathbf{F i}$ & Fr & Ge & Gr & Ir & It & $\mathbf{L u}$ & NI & Po & Sp & $\overline{\text { Uk }}$ \\
\hline \multirow[t]{5}{*}{ Male } & $\begin{array}{c}<\text { Second } \\
\text { level }\end{array}$ & 31.0 & 20.8 & 52.3 & 38.6 & 27.8 & 45.1 & 33.4 & 28.9 & 43.5 & 46.0 & 69.3 & 71.7 & 43.2 & 39.9 \\
\hline & Second level & 66.9 & 33.0 & 35.2 & 56.5 & 24.9 & 45.9 & 50.5 & 41.3 & 50.9 & 41.7 & 26.6 & 24.0 & 35.9 & 20.8 \\
\hline & Third lev. & 2.0 & 17.1 & 2.1 & 4.6 & 19.7 & 4.5 & 13.0 & 12.6 & 5.3 & 9.8 & 1.6 & 3.8 & 20.8 & 38.4 \\
\hline & Still studying & 0.2 & 30.1 & 10.4 & 0.3 & 27.6 & 4.5 & 3.1 & 17.2 & 0.3 & 2.5 & 2.5 & 0.5 & 0.1 & 0.9 \\
\hline & Total & 100 & 100 & 100 & 100 & 100 & 100 & 100 & 100 & 100 & 100 & 100 & 100 & 100 & 100 \\
\hline \multirow[t]{5}{*}{ Female } & $\begin{array}{c}<\text { Second } \\
\text { level }\end{array}$ & 42.5 & 19.2 & 49.7 & 49.8 & 22.9 & 47.5 & 20.8 & 20.5 & 34.9 & 49.0 & 71.3 & 58.3 & 32.1 & 38.0 \\
\hline & Second level & 53.9 & 32.7 & 30.1 & 42.9 & 21.1 & 40.5 & 55.5 & 45.7 & 58.1 & 40.9 & 23.4 & 33.4 & 42.1 & 19.7 \\
\hline & Third lev. & 3.1 & 17.5 & 5.4 & 7.2 & 21.1 & 3.6 & 19.4 & 14.8 & 6.8 & 7.4 & 2.3 & 6.9 & 25.7 & 41.0 \\
\hline & Still studying & 0.5 & 30.6 & 14.8 & 0.1 & 34.5 & 8.4 & 4.0 & 19.0 & 0.2 & 2.7 & 3.0 & 1.4 & 0.1 & 1.3 \\
\hline & Total & 100 & 100 & 100 & 100 & 100 & 100 & 100 & 100 & 100 & 100 & 100 & 100 & 100 & 100 \\
\hline
\end{tabular}

Source: ECHP waves 1-8 
Table 3

Indicators of marriage, labor and housing markets, and proxies for the welfare state and culture: international comparisons

\begin{tabular}{|c|c|c|c|c|c|}
\hline Country & $\begin{array}{l}\text { Average } \\
\text { Sex ratio }\end{array}$ & $\begin{array}{c}\text { Average } \\
\text { Unemployment } \\
\text { rate }\end{array}$ & $\begin{array}{c}\text { Maximum Loan } \\
\text { To Value ratio }\end{array}$ & $\begin{array}{c}\text { Youth social } \\
\text { expenditure }(\% \\
\text { total public } \\
\text { expenditure) }\end{array}$ & $\begin{array}{l}\text { Important child } \\
\text { quality: } \\
\text { independence } \\
\text { (\% parents) }\end{array}$ \\
\hline Austria & 49.35 & 3.75 & 80 & 3.47 & 63.4 \\
\hline Belgium & 49.22 & 8.40 & 80 & 6.57 & 36.4 \\
\hline Denmark & 49.08 & 8.17 & 80 & 11.71 & 82.8 \\
\hline Finland & 48.90 & -- & 80 & 8.37 & 57.9 \\
\hline France & 49.53 & 9.45 & 80 & 9.03 & 25.9 \\
\hline Germany & 48.36 & 8.81 & 80 & 7.22 & 62.6 \\
\hline Greece & 48.28 & 7.49 & 75 & 5.86 & 50.6 \\
\hline Ireland & 49.41 & 8.30 & 80 & 14.28 & 47.2 \\
\hline Italy & 49.51 & 15.44 & 60 & 1.79 & 33.9 \\
\hline Luxembourg & 49.31 & 2.20 & 60 & 2.25 & 44.6 \\
\hline Netherlands & 49.14 & 3.92 & 75 & 10.07 & 52.7 \\
\hline Portugal & 49.65 & 3.83 & 80 & 4.64 & 18.1 \\
\hline Spain & 49.07 & 17.18 & 80 & 6.19 & 31.1 \\
\hline U.K. & 48.69 & 5.06 & 95 & 10.08 & 46.6 \\
\hline
\end{tabular}

Note. Average Sex Ratio computed as female population over total population in the age band 18-34, by country regions from REGIO dataset (EUROSTAT), 1994-2001. Average unemployment rate from REGIO dataset refers to the same years and country regions. Maximum Loan-To-Value ratio is drawn from Chiuri and Jappelli (2003) and Maclennan, Muellbauer and Stephens (1998); it refers to the 1990 decade. Youth social expenditure as percentage of total public expenditure is from OECD SOCX database, it includes housing, active labor market policies and policies for other contingencies as income support programs; the values reported in the Table is a 1994-2001 average. The last column is drawn from the World Value Survey (1990 and 2000) and reports the percentage of interviewed aged between 35 and 70 that declared as an important child quality: independence. 
Table 4 Results from a Cox proportional hazard model.

\begin{tabular}{|c|c|c|c|}
\hline Model & (1) & (2) & (3) \\
\hline D man & $0.653(0.015)^{* * *}$ & $0.602(0.022)^{* * *}$ & $0.614(0.023)^{* * *}$ \\
\hline N. siblings & $1.064(0.011)^{* * *}$ & $1.049(0.013)^{* * *}$ & $1.074(0.013)^{* * *}$ \\
\hline High educated & $1.007(0.030)$ & $0.911(0.032)^{* * *}$ & $1.023(0.039)$ \\
\hline High educated mother & $1.489(0.062)^{* * *}$ & $1.320(0.064)^{* * *}$ & $1.161(0.057)^{* * *}$ \\
\hline High educated father & $1.295(0.046)^{* * *}$ & $1.218(0.049)^{* * *}$ & $1.137(0.048)^{* * *}$ \\
\hline Working mother & $1.620(0.039)^{* * *}$ & $1.468(0.044)^{* * *}$ & $1.317(0.042)^{* * *}$ \\
\hline D grandparent & $0.106(0.017)^{* * *}$ & $0.091(0.018)^{* * *}$ & $0.109(0.022)^{* * *}$ \\
\hline Sex ratio (in \%) & & $1.055(0.016)^{* * *}$ & $1.055(0.017)^{* * *}$ \\
\hline Unemployment rate & & $0.975(0.002)^{* * *}$ & $0.984(0.003)^{* * *}$ \\
\hline Down payment ratio & & $0.954(0.002)^{* * *}$ & $0.958(0.003)^{* * *}$ \\
\hline $\begin{array}{l}\text { Youth social } \\
\text { expenditure (in \%) }\end{array}$ & & & $1.038(0.009)^{* * *}$ \\
\hline $\begin{array}{l}\text { Independence as child } \\
\text { quality for parents }\end{array}$ & & & $0.998(0.001)$ \\
\hline $\begin{array}{l}\text { D Northern non- } \\
\text { continental countries }\end{array}$ & & & $0.889(0.080)$ \\
\hline $\begin{array}{l}\text { D Northern Continental } \\
\text { countries }\end{array}$ & & & $4.243(0.457)^{* * *}$ \\
\hline $\begin{array}{l}\text { D Central West } \\
\text { countries }\end{array}$ & & & $1.903(0.077)^{* * *}$ \\
\hline N. Observations & 119,520 & 80,368 & 80,368 \\
\hline Log Likelihood & $-67,402.849$ & $-43,766.143$ & $-43,336.194$ \\
\hline
\end{tabular}

Note: Coefficients reported are hazard ratio. Robust standard errors in parentheses

* significant at $10 \% ; * *$ significant at $5 \% ; * * *$ significant at $1 \%$ 
Table 5 Estimates of a Cox proportional hazard model by gender differences.

\begin{tabular}{|c|c|c|c|}
\hline Variables & Sample & Men & Women \\
\hline N. siblings & & $1.065(0.019)^{* * *}$ & $1.091(0.018)^{* * *}$ \\
\hline High educated & & $1.053(0.055)$ & $0.998(0.053)$ \\
\hline High educated mother & & $1.292(0.091)^{* * *}$ & $1.041(0.071)$ \\
\hline High educated father & & $1.209(0.075)^{* * *}$ & $1.059(0.061)$ \\
\hline Working mother & & $1.291(0.058)^{* * *}$ & $1.308(0.058)^{* * *}$ \\
\hline D grandparent & & $0.134(0.034)^{* * *}$ & $0.084(0.027)^{* * *}$ \\
\hline Sex ratio (in \%) & & $0.879(0.022)^{* * *}$ & $1.167(0.027)^{* * *}$ \\
\hline Unemployment rate & & $0.969(0.005)^{* * *}$ & $0.984(0.003)^{* * *}$ \\
\hline Down payment ratio & & $0.957(0.004)^{* * *}$ & $0.961(0.004)^{* * *}$ \\
\hline $\begin{array}{l}\text { Youth social } \\
\text { expenditure (in \%) }\end{array}$ & & $1.031(0.012)^{* * *}$ & $1.045(0.012)^{* * *}$ \\
\hline $\begin{array}{l}\text { Independence as child } \\
\text { quality for parents }\end{array}$ & & $0.990(0.002)^{* * *}$ & $0.997(0.002)^{*}$ \\
\hline $\begin{array}{l}\text { D Northern non- } \\
\text { continental countries }\end{array}$ & & $1.152(0.138)$ & $0.819(0.107)$ \\
\hline $\begin{array}{l}\text { D Northern Continental } \\
\text { countries }\end{array}$ & & $6.404(1.002)^{* * *}$ & $4.350(0.668)^{* * *}$ \\
\hline $\begin{array}{l}\text { D Central West } \\
\text { countries }\end{array}$ & & $1.994(0.107)^{* * *}$ & $1.909(0.112)^{* * *}$ \\
\hline Observations & & 45,942 & 34,426 \\
\hline Log Likelihood & & $-20,048.02$ & $-19,832.702$ \\
\hline
\end{tabular}


Table 6 Estimates of a Cox proportional hazard model by group of countries

\begin{tabular}{|c|c|c|c|c|}
\hline & (1) & (2) & (3) & (4) \\
\hline Variables & $\begin{array}{l}\text { Northern non- } \\
\text { contin. countries }\end{array}$ & $\begin{array}{l}\text { Northern contin. } \\
\text { countries }\end{array}$ & $\begin{array}{l}\text { Central West } \\
\text { countries }\end{array}$ & Mediter. countries \\
\hline $\mathrm{D}$ man & $0.749(0.085)^{* *}$ & $0.421(0.191)^{*}$ & $0.522(0.031)^{* * *}$ & $0.568(0.040)^{* * *}$ \\
\hline N. siblings & $1.081(0.030)^{* * *}$ & $1.059(0.033)^{*}$ & $1.127(0.022)^{* * *}$ & $1.179(0.023)^{* * *}$ \\
\hline High educated & $1.119(0.100)$ & $0.680(0.112)^{* *}$ & $1.072(0.061)$ & $1.030(0.050)^{*}$ \\
\hline $\begin{array}{l}\text { High educated } \\
\text { mother }\end{array}$ & $1.191(0.133)$ & $1.241(0.120)^{* *}$ & $1.111(0.078)$ & $1.206(0.103)^{* *}$ \\
\hline $\begin{array}{l}\text { High educated } \\
\text { father }\end{array}$ & $1.295(0.126)^{* * *}$ & $0.997(0.095)$ & $1.064(0.062)$ & $1.143(0.074)^{* *}$ \\
\hline Working mother & $0.882(0.078)$ & $1.596(0.210)^{* * *}$ & $1.254(0.053)^{* * *}$ & $1.160(0.067)^{* * *}$ \\
\hline D grandparent & $0.493(0.297)$ & $0.000(0.000)$ & $0.052(0.031)^{* * *}$ & $0.137(0.031)^{* * *}$ \\
\hline Sex ratio (in \%) & $0.882(0.045)^{* *}$ & $1.110(0.241)$ & $1.020(0.025)$ & $1.107(0.026)^{* * *}$ \\
\hline Unempl. rate & $0.737(0.021)^{* * *}$ & $0.682(0.069)^{* * *}$ & $0.949(0.007)^{* * *}$ & $0.969(0.006)^{* * *}$ \\
\hline $\begin{array}{l}\text { Down payment } \\
\text { Ratio }\end{array}$ & $0.948(0.021)^{* *}$ & $1.035(0.018)^{* *}$ & $0.885(0.005)^{* * *}$ & $0.900(0.021)^{* * *}$ \\
\hline $\begin{array}{l}\text { Youth social } \\
\text { exp. (in \%) }\end{array}$ & $2.364(0.247)^{* * *}$ & $1.672(0.250)^{* * *}$ & $0.923(0.018)^{* * *}$ & $2.084(0.087)^{* * *}$ \\
\hline $\begin{array}{l}\text { Indep. as child } \\
\text { qual. for par. }\end{array}$ & $1.022(0.018)$ & $0.654(0.093)^{* * *}$ & $1.021(0.003)^{* * *}$ & $0.983(0.006)^{* * *}$ \\
\hline D Ireland & $0.036(0.022)^{* * *}$ & & & \\
\hline D Denmark & & $3.344(8.690)$ & & \\
\hline D Greece & & & & $0.008(0.003)^{* * *}$ \\
\hline D Spain & & & & $0.003(0.001)^{* * *}$ \\
\hline D Portugal & & & & $0.005(0.003)^{* * *}$ \\
\hline D Germany & & & $0.585(0.071)^{* * *}$ & \\
\hline D Netherlands & & & $1.157(0.131)$ & \\
\hline D Belgium & & & $0.558(0.044)^{* * *}$ & \\
\hline D Austria & & & $0.108(0.016)^{* * *}$ & \\
\hline Observations & 9,288 & 2,453 & 29,463 & 39,164 \\
\hline Log Likelihood & -4025.6723 & -2443.7774 & $-17,442.853$ & $-12,899.782$ \\
\hline
\end{tabular}

Note: Coefficients reported are hazard ratio. Robust standard errors in parentheses

$*$ significant at $10 \% ; * *$ significant at $5 \% ; * * *$ significant at $1 \%$ 